\title{
Improvements in the Structure of Electrospun Polyurethane Nanofibrous Materials Used for Bacterial Removal from Wastewater
}

\author{
Jaroslav Lev \\ Mendel University of Brno, Faculty of Agronomy, \\ Department of Engineering and Automobile Transport/ASIO, spol. s r.o. \\ Zemedelska 1, 61300 Brno, Czech Republic/Turanka 1, 62700 Brno, Czech Republic \\ lev@asio.cz \\ Marek Holba \\ Institute of Botany of the Academy of Science of the Czech Republic, \\ Department of Experimental Phycology and Ecotoxicology/ASIO, spol. s r.o. \\ Lidicka 25/27, 60200 Brno, Czech Republic/Turanka 1, 62700 Brno, Czech Republic \\ holba@asio.cz \\ Libor Kalhotka \\ Mendel University of Brno, Faculty of Agronomy, \\ Department of Agrochemistry, Soil Science, Microbiology and Plant Nutrition \\ Zemedelska 1, 61300 Brno, Czech Republic \\ xkalhotk@node.mendelu.cz \\ Premysl Mikula \\ Institute of Botany of the Academy of Science of the Czech Republic, \\ Department of Experimental Phycology and Ecotoxicology \\ Lidicka 25/27, 60200 Brno, Czech Republic \\ premysl.mikula@centrum.cz

\section{Dusan Kimmer} \\ SPUR, a.s. \\ T. Bati 299, 76422 Zlin, Czech Republic \\ kimmerdusan@spur.cz
}

\begin{abstract}
While the properties of electrospun nanofibrous materials appear promising for filter applications, the ideal material parameters for water filtration are still being investigated. Polyurethane (PU) nanofiber layered on a supporting polypropylene (PP) textile is a good candidate for pathogen removal from water. Here, we show experimentally that pathogen removal from wastewater up to log 4.86 can be achieved using electrospun PU nanofibers. Materials with different area weights $\left(0.3,0.5,1.9\right.$ and $\left.3.8 \mathrm{~g} / \mathrm{m}^{2}\right)$ were used for filtering E. coli from artificial wastewater. Tests were carried
\end{abstract}

out at 50 and $100 \mathrm{kPa}$ pressure. Bacterial contamination was analyzed by both cultivation in nutrient agar medium and by flow cytometry (FCM). Both methods showed low pathogen removal efficiency (log 0.88 to 0.98) using filter materials ranging from 0.3 to $1.9 \mathrm{~g} / \mathrm{m}^{2}$, and high removal rates (log 4.10 to 4.86) using filters of $3.8 \mathrm{~g} / \mathrm{m}^{2}$ area weight, results comparable with the best commercial microfiltration membranes. 
Keywords: Nanofibers, Electrospinning, Wastewater Treatment, Filtration Properties, Pathogen Removal.

(C) Copyright 2012 Authors - This is an Open Access article published under the Creative Commons Attribution License terms (http://creativecommons.org/licenses/by/2.0). Unrestricted use, distribution, and reproduction in any medium are permitted, provided the original work is properly cited.

\section{Introduction}

Bacterial contamination of water is a serious worldwide problem. Currently, chemical disinfectants, such as chlorine, or UV disinfection are employed to control microbial pathogens. Application of the above-mentioned methods, however, has a number of limiting factors, such as the formation of harmful disinfection byproducts from chemical disinfectants and high operating costs (Li et al., 2008). The use of alternative water treatments, on the other hand, such as conventional ultrafiltration or nanofiltration through porous membranes, typically manufactured using phase immersion, have been discriminated against as they provide relatively low flux rates considering their high prices (Yoon et al., 2006). Highly porous electrospun nanofibers and nanobiocides possess great potential for improving water filtration processes (Botes et al., 2010). Nanofibers are produced through a relatively simple method, i.e. electrospinning, which has encouraged many research teams to study nanofiber applications for removal of bacteria, particles (Gopal et al., 2006) or dye from potable water (Botes et al., 2010) or wastewater (Bjorge et al., 2009).

Nanofibres have a small pore size and large surface area to volume ratio compared to non-woven materials. For a nanofiber, this ratio can be as large as $10^{3}$ times that of a microfiber. This, together with its low density and interconnected open-pore structure, makes non-woven nanofiber appropriate for a wide variety of filtration applications (Huang et al., 2003). For example, nanofibers, or modified nanofibers, have been proposed as potential membranes for applications in separation technology, such as pre-treatment of water prior to reverse osmosis or as filters or pre-filters minimizing the risk of fouling and contamination prior to ultra- or nanofiltration applications in water treatment technologies (Gopal et. al., 2006).

Our previous preliminary studies (Holba et al. 2011; Lev et al., 2011; Mikula et al., 2012) introduced special filtration materials that were prepared by layering polyurethane nanofibers onto PP microfiber supporting tissue; these materials providing high mechanical resistance and efficiency. In this study, we focus on nanofiber layer optimization for more efficient removal of bacteria.

\section{Material and Methods \\ 2.1. Material Preparation}

A PU solution in dimethylformamide (DMF) was synthesized based on 4,4'-methylene-bis(phenylisocyanate)
(MDI), poly(3-methyl-1,5-pentanediol)-alt-(adipic, isophtalic acid) (PAIM) and 1,4 butanediol (BD) at a molar ratio of 9:1:8 at $90^{\circ} \mathrm{C}$ for 5 hours (3 synthesis steps starting with preparation of the pre-polymer from MDI and PAIM, followed by addition of $\mathrm{BD}$ and the remaining quantity of MDI). PU density was $\rho=1.09 \mathrm{~g} / \mathrm{cm}^{3}$. The prepared solutions were suitable for electrospinning and had a PU concentration of $13.5 \mathrm{wt} \%$, a viscosity of $1.5 \mathrm{~Pa} \cdot \mathrm{s}$, and conductivity of 156 $\mu \mathrm{S} / \mathrm{cm}$.

Nanofiber layers were prepared from the polymeric solutions using a commercially available NanoSpider ${ }^{\mathrm{TM}}$ machine (Elmarco s.r.o. Liberec, Czech Republic, http://www.elmarco.com/) equipped with a patented rotating electrode with 3 cotton cord spinning elements (PCT/CZ2010/000042) or a set of nanofiber-forming jets. The experimental conditions were as follows: $32 \%$ relative humidity, $24^{\circ} \mathrm{C}$ temperature, $75 \mathrm{kV}$ voltage applied to the $\mathrm{PU}$ solution, $210 \mathrm{~mm}$ distance between electrodes, and $7 \mathrm{rpm}$ rotational electrode speed. The nanofibers were collected on polypropylene textiles spun at 0.12 to $0.32 \mathrm{~m} / \mathrm{min}$.

The nanofiber filter produced through the electrospinning process was characterized using a Scanning Electron Microscope (Vega 3, Tescan, Czech Republic).

A range of flat sheet non-woven nanofiber membrane layers (see Figs. 1 and 2) were produced with area weight of $0.3,0.5,1.9$ and $3.8 \mathrm{~g} / \mathrm{m}^{2}$. In each case, nanofiber diameter ranged between 80 and $250 \mathrm{~nm}$ and pore size distribution from 50 to $430 \mathrm{~nm}$. A circular filter with a diameter of $48 \mathrm{~mm}$ (functional diameter $38 \mathrm{~mm}$ ) was then cut from the four nanofibrous layers. The filters were sterilized through 4 hour exposure to UV radiation prior to the experiment.
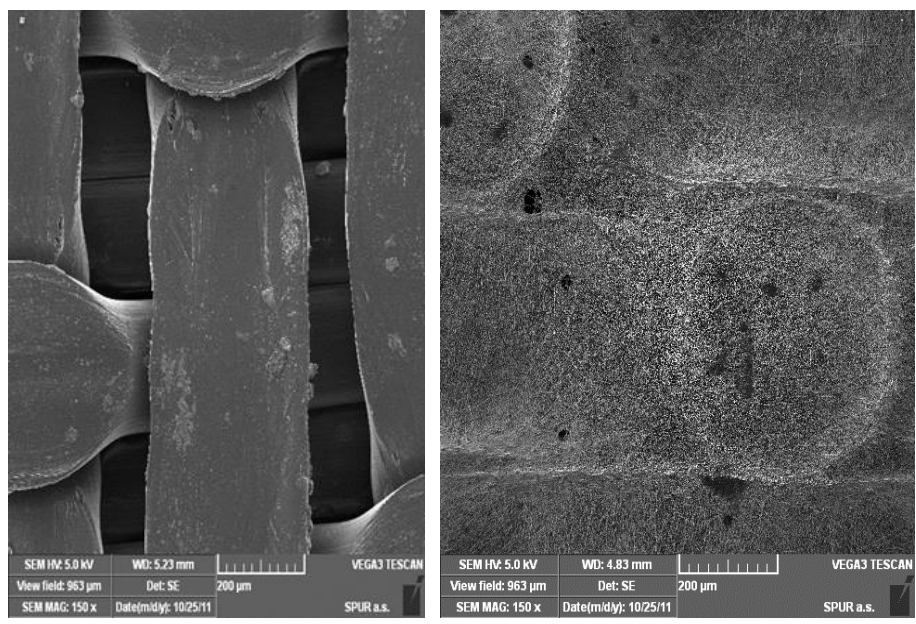

Fig. 1. A polypropylene matrix (left; magnification $150 \times$ ) and the polyurethane nanofiber layer (right; magnification 150×)

\subsection{Filtration Experiments \\ 2.2.1 Synthetic Wastewater}

A sterile bouillon was inoculated with E. coli CCM 3988. After 24 hours of cultivation at $37^{\circ} \mathrm{C}, 10 \mathrm{~mL}$ of culture was inoculated into $1000 \mathrm{~mL}$ of sterile distilled water to obtain 
synthetic wastewater containing around $5 \times 10^{6}$ cells per mL. This was then poured into the sterilized filtration device (Fig. 3).

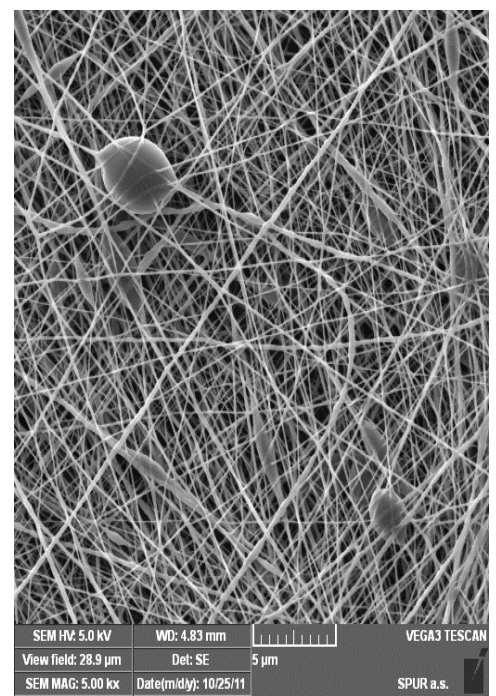

Fig. 2. The polyurethane (PU) nanofiber layer (magnification 5000×)

\subsubsection{Filtration Device}

A nanofiber filter with supporting media was fixed into the device's holder and air pressure set to $50 \mathrm{kPa}$ or $100 \mathrm{kPa}$ by adjustment of a valve. The water sample (100 mL) was then transferred to the filter via a drain valve. Flux was determined by time of filtration. Filtered water samples were collected and diluted as needed for further analysis.



Fig. 3. Experimental filtration device

\subsubsection{Inoculation in E. coli Nutrient Agar Culture Medium}

Samples of both filtered and non-filtered medium were analyzed through standard methodology (EN ISO 6222:1999 and EN ISO 9308-1:2000) via inoculation into an E. coli nutrient agar culture medium. Decimal dilutions of model wastewater (non-filtered as control; plus samples filtered through each filter type) were prepared and $1 \mathrm{~mL}$ of each dilution was inoculated onto a sterile Petri dish filled with Endo agar (Merck, Germany) nutrient medium. The samples were incubated for $72 \mathrm{~h}$ at $37^{\circ} \mathrm{C}$. E. coli colonies were counted and number of bacteria calculated and expressed as colonyforming units per $\mathrm{mL}(\mathrm{CFU} / \mathrm{mL})$.

\subsubsection{Flow-Cytometric (FCM) Analysis}

Control (i.e. non-filtered) samples of E. coli bacterial suspensions and samples filtered through the different nanomaterial area weight were analyzed using the CyFlow ML (Partec, Muenster, Germany) flow cytometer equipped with a blue laser $(\lambda=488 \mathrm{~nm})$ and 4 optical parameters (FSC, SSC, FL1 and FL2). The flow cytometer enables accurate detection of bacteria in water samples at concentrations higher than ca. $1 \times 10^{4}$ cells per mL. At bacterial concentrations lower than this it is difficult to distinguish bacteria from background noise on the cytograms. Before measurement of total bacterial count, samples were stained using SYBR Green I and incubated for 15 minutes in the dark, according to Marie et al. (1997). Bacteria were identified based on their green and red fluorescence on two-parametric dot-plots of FL1 $(527 / 30 \mathrm{~nm})$ and FL2 (>630 nm), respectively (Hammes et al., 2008).

\subsubsection{Filtration Efficiency Determination}

The results of our filtration experiments were expressed by log removal values. These values describe a decrease in the numbers of bacteria caused by filtration expressed in orders of magnitude detected by both analytical methods (i.e. $\mathrm{CFU} / \mathrm{mL}$ determined by plating and total bacterial counts in cells per mL detected by flow cytometry) according to the formula:

$y=\log _{a} x \quad \Leftrightarrow \quad a^{y}=x$

$\mathrm{y}$ - $\log$ scale value for bacteria

$\mathrm{x}$ - decimal scale value for bacteria $[\mathrm{CFU} / \mathrm{mL}]$

$\mathrm{a}=10$

\section{Results and Discussion}

Filtration efficiency is a parameter commonly used for both characterization of materials and investigation of their suitability in water treatment processes. Various analytical approaches may be used to determine filtration efficiency. While Bazargan et al. (2011) used a specialized optical particle counter for assessment of particle removal from water we, along with other authors (Gopal et al., 2006; Bjorge et al., 2009; Desai et al., 2009) prefer the use of bacteria for 
filtration experiments as they better reflect real conditions. Two different analytical methods were used for nanomaterial filtration efficiency assessment (FCM and cultivation), each resulting in slightly different bacterial counts. However, this observation is not surprising as FCM detects all bacteria in a sample, regardless of their physiological state (i.e. active/viable and inactive/non-viable), whereas cultivation techniques only detect bacteria that are both viable and cultivable (i.e. able to grow and form colonies on specific nutrient media under defined standardized conditions).

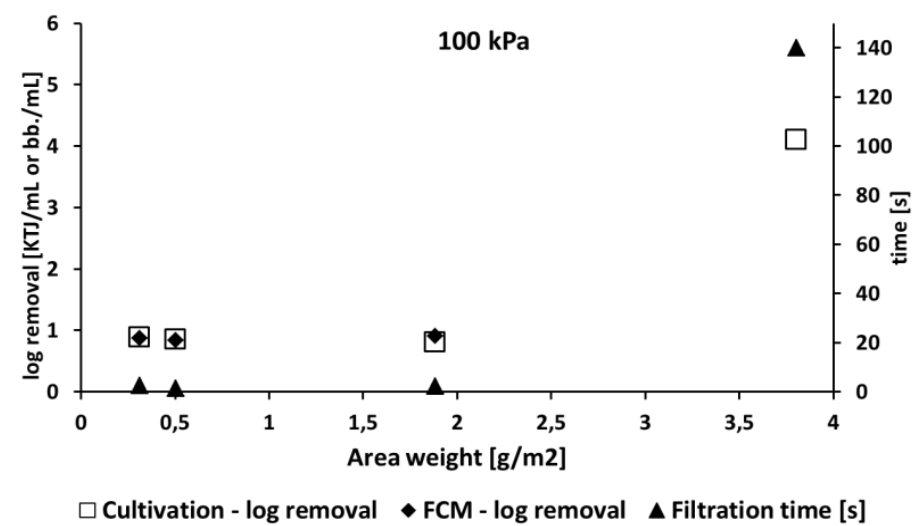

Fig. 4. Results for filtration under $100 \mathrm{kPa}$ pressure. The FCM log removal value for material of area weight $3.8 \mathrm{~g} / \mathrm{m}^{2}$ is not depicted as the number of bacteria detected was lower than the limit of detection (see also section 2.2.4).

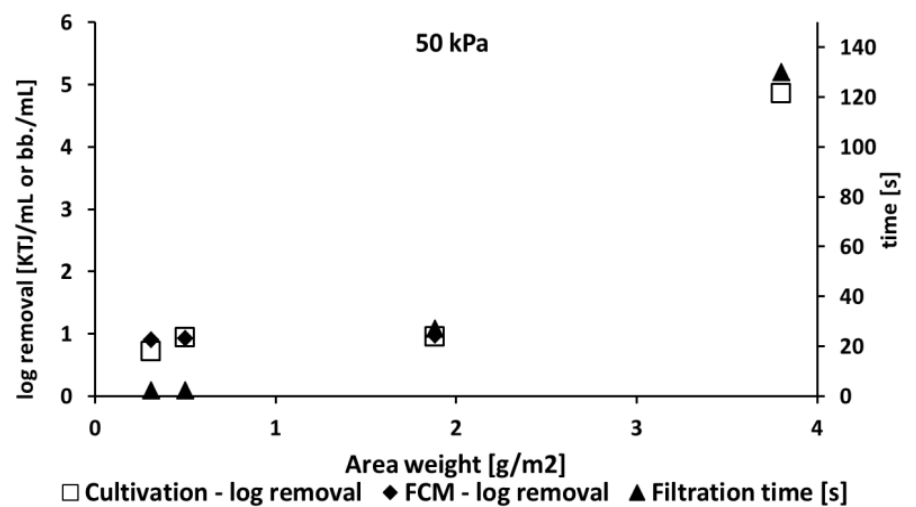

Fig. 5. Results for filtration under $50 \mathrm{kPa}$ pressure. The FCM log removal value for material of area weight $3.8 \mathrm{~g} / \mathrm{m}^{2}$ is not depicted as the number of bacteria detected was lower than the limit of detection (see also section 2.2.4).

Log bacterial removal counts were comparable using both methods, with low removal efficiency ( $\log 0.88$ to 0.98 ) using filters with lower area weight from 0.3 to $1.88 \mathrm{~g} / \mathrm{m}^{2}$ area weight, and relatively high efficiency ( $\log 4.1$ to 4.86 ) using material of $3.8 \mathrm{~g} / \mathrm{m}^{2}$ area weight.

Filtration pressure (50 or $100 \mathrm{kPa}$ ) had little influence on filtration efficiency. Filtration overpressure was chosen based on previous laboratory-scale tests at $100 \mathrm{kPa}$. This value was chosen based on the area of the nanofiber filter (38 $\mathrm{mm}$ ) since the filter quickly becomes clogged and lower pressures lead to lower flux. We verified that pressure did not influence the filtration parameters by testing at $50 \mathrm{kPa}$, which better simulates real conditions.

Our results are similar to those of Bjorge (2009), who investigated removal of $E$. coli from hospital wastewater. While Bjorge (2009) initially achieved log removal values ranging from 1.7 to 2.1 , bacterial removal was significantly improved by functionalizing the nanofiber with silver (Ag), whereupon log removal values rose to 4.01 . The highest bacterial log removal value detected in our study (4.86) confirms both the high quality of the nanomaterials used and their suitability for wastewater filtration processes. This value is even comparable to those of Gomez et al. (2006), who reported bacteria removal values in the order of 4 to 6 during experiments with commercial microfiltration membranes. Despite both Bjorge et al. (2009) and Gomez et al. (2006) not specifying area weights of their filtration materials, our results confirm the hypothesis that area weight represents a crucial parameter for material filtration efficiency assessment.

Even more efficient bacterial removal values could be expected if the nanofibers used were to be modified using biocidal substances or functional structures such as metal and metal oxide nanoparticles (e.g. nanoAg, $\mathrm{ZnO}, \mathrm{CuO}, \mathrm{TiO}_{2}$, or engineered/synthesized nanomaterials such as fullerenes and carbon nanotubes) or natural antibacterial or antimicrobial substances such as chitosan (Li et al., 2008). Nanofiber functionalization is an excellent tool for bacterial removal as the use of biocidal substances allows the use of thinner nanofiber layers and improves the flux rate, with similar or even better bacterial removal.

Our future research will cover the problems of low filter mechanical resistance, stability of the supporting layer and removal of biofouling.

\section{Conclusion}

Electrospun nanofibers show great potential for use in filtration applications. We compared nanofibrous layers with different area weight and found a value of $3.8 \mathrm{~g} / \mathrm{m}^{2}$ best; achieving values up to 4.86, comparable with the best commercial water treatment membranes. Future work will be focused on detailed materials testing and production optimization, with specific properties based on area weight. FCM was shown to be a suitable analytical method for measurement of nanofiber filtration efficiency and may be used as an alternative to more commonly performed plating techniques. Membrane functionalization, the next step in our research, should lead to increased pathogen removal efficiency.

\section{Acknowledgements}

This study was financed by the Technology Agency of the Czech Republic, grant no. TA01010356. This study was also 
partly supported as a long-term research development project no. RVO 67985939 (Institute of Botany of the ASCR).

\section{References}

Bazargan, A. M., Keyanpour-rad, M., Hesari, F. A., Ganji, M. E. (2011). A study on the microfiltration behavior of selfsupporting electrospun nanofibrous membrane in water using an optical particle counter. Desalination, 265, 148152.

Bjorge, D., Daels, N., De Vrieze, S., Dejans, P., Van Camp, T., Audenaert, W., Hogie, J., Westbroek, P., De Clerck, K., Van Hulle, W. H. S. (2009). Performance assessment of electrospun nanofibers for filter applications, Desalination 249, 942-948.

Botes, M., Cloete, T. E. (2010). The potential of nanofibers and nanobiocides in water purification. Critical Reviews in Microbiology, 36, 68-81.

Cloete, T. E., de Kwaadsteniet, M., Botes, M., Lopez-Romero, J. M. (2010). Nanotechnology in Water Treatment Applications, Caister Academic Press.

Desai, K., Kit, K., Li, J. J., Davidson, P. M., Zivanovic, S., Meyer, H. (2009). Nanofibrous chitosan non-wovens for filtration applications. Polymer, 50, 3661-3669.

EN ISO 6222:1999 Water quality - Enumeration of culturable micro-organisms - Colony count by inoculation in a nutrient agar culture medium.

EN ISO 9308-1:2000. Water quality - Detection and enumeration of Escherichia coli and coliform bacteria.

Gomez, M., de la Rua, A., Garralon, G., Plaza F., Hontoria, E., Gomez, M. A. (2006). Urban wastewater disinfection by filtration technologies, Desalination, 190, 16-28.

Gopal, R., Kaur, S., Ma, Z., Chan, C., Ramakrishna, S., Matsuura, T. (2006). Electrospun nanofibrous filtration membrane, Journal of Membrane Science, 281, 581-586.

Hammes, F., Berney, M., Wang, Y. Y., Vital, M., Koster, O., Egli, T. (2008). Flow-cytometric total bacterial cell counts as a descriptive microbiological parameter for drinking water treatment processes. Water Research, 42, 269-277.

Holba, M., Lev, J., Kalhotka, L., Szostkova, M., Kimmer, D. (2011). Use of electrospun nano-fibers for bacteria removal from wastewater treatment plants outlets, Proc. of Int. Conf. International water week Amsterdam 2011, Amsterdam, Netherlands, 29 Oct. - 4 Nov., p.77.

Huang, Z-M., Zhang, Y-Z., Kotaki M., Ramakrishna, S. (2003). A review on polymer nanofibres by electrospinning and their applications in nanocomposites, Composites Science and Technology, 63, 2223-2253

Lev, J., Holba, M., Kalhotka, L., Szostkova, M., Kimmer, D., (2011). Application of the Electrospun Nanofibers in Wastewater Treatment, Proceedings of the International Conference NANOCON 2011, Brno, Czech Republic, 21-23. Oct. p. $120-126$.

Li, Q. L., Mahendra, S, Lyon D. Y., Brunet, L., Liga M. V., Li, D, Alvarez, P. J. J. (2008). Antimicrobial nanomaterials for water disinfection and microbial control, Potential applications and implications. Water Research, 42, 45914602.

Marie, D., Partensky, F., Jacquet, S., Vaulot, D. (1997). Enumeration and cell cycle analysis of natural populations of marine picoplankton by flow cytometry using the nucleic acid stain SYBR Green I. Applied and Environmental Microbiology 63, 186-193.

Mikula, P., Lev, J., Kalhotka, L., Holba, M., Kimmer, D., Marsalek, B., Vitezova, M. (2012). Vyuziti prutokove cytometrie pro detekci ucinnosti filtrace bakterii $\mathrm{v}$ procesech cisteni odpadnich vod (The use of flow cytometry for assessing the effectiveness of bacterial filtration during wastewater treatment). In: RihovaAmbrozova, J., Vesela, J. (eds.) Conference "Vodarenska biologie 2012, 2.-3. Feb, Prague, Czech Republic, p. 193199. (in Czech).

Yoon, K., Kim, K., Wang, X., Fang, D., Hsiao, B. S, Chu, B. (2006). High flux ultrafiltration membranes based on electrospun nanofibrous PAN scaffolds and chitosan coating, Polymer, 47, 2434-2441. 